\title{
Pembangunan Permainan Video Action-Shooter 2 Dimensi Berbasis Desktop Menggunakan Game Maker Studio 1.4
}

\author{
Harya Bima Dirgantara ${ }^{1)}$, Paramaresthi Windriyani ${ }^{2)}$ \\ Informatika, Fakultas Industri Kreatif Institut Teknologi dan Bisnis Kalbis \\ Jalan Pulomas Selatan Kav. 22, Jakarta 13210 \\ ${ }^{1)}$ Email: harya.dirgantara@kalbis.ac.id \\ ${ }^{2)}$ Email: paramaresthi.windriyani@kalbis.ac.id
}

\begin{abstract}
This study aims to build a 2-dimensional action-shooter video game using Game Maker Studio. This video game will have two types of gameplay, namely by shooting enemies and capturing enemies. The video game will be built using the Game Development Life Cycle (GDLC) process model, which consists of stages: initiation, pre-production, production, testing, beta, and release. The result of this research is that the desktop-based 2-dimensional beta version of the video game prototype can run according to its function.
\end{abstract}

Keywords: action-shooter, desktop, game development life cycle, video game

\begin{abstract}
Abstrak: Penelitian ini bertujuan untuk membangun permainan video bergenre action-shooter 2 dimensi menggunakan Game Maker Studio. Permainan video ini akan memiliki dua tipe gameplay yaitu dengan cara menembak musuh dan menangkap musuh. Permainan video akan dibangun menggunakan model proses Game Development Life Cycle (GDLC) yang terdiri dari tahap: inisiasi, pre-produksi, produksi, testing, beta, dan rilis. Hasil dari penelitian ini adalah purwarupa versi beta permainan video 2 dimensi yang berbasis desktop dapat berjalan sesuai dengan fungsinya.
\end{abstract}

Kata kunci: action-shooter, desktop, game development life cycle, permainan video

\section{PENDAHULUAN}

Permainan video merupakan hal yang sering dimainkan untuk mengisi waktu luang dan dijadikan hiburan bagi masyarakat saat ini. Salah satu jenis permainan video yang populer adalah action-shooter. Pada tahun 2018, tingkat popularitas permainan video action-shooter adalah 26,9\% [1]. Sedangkan platform permainan video yang banyak dibangun pada tahun 2019 adalah platform personal computer (PC) [2].

Bermain permainan video, terutamagenreactionshooter dapat meningkatkan kemampuan kognitif, antara lain kemampuan sensitivias visual, kecepatan pemrosesan perseptual, dan pengambilan keputusan perseptual [3][4]. Permainan video action-shooter adalah sebuah permainan video yang memiliki fitur, dinamik, dan mekanik yang dapat mengubah persepsi dasar, perhatian, dan kemampuan kognitif. Permainan ini dikarakteristikan dengan setting permainan yang khusus, target yang bergerak atau berubah dengan cepat, pemrosesan peripheral yang kuat, dan fokus tinggi agar akurat [3]. Tujuan penelitian ini adalah untuk membangun permainan video action-shooter 2 dimensi. Permainan video action-shooter ini memiliki ruang lingkup yaitu: permainan single player, berjalan pada platform desktop, memiliki dua fitur gameplay, yaitu menangkap dan menembak musuh.

\section{METODE PENELITIAN}

\section{A. Permainan Video}

Menurut Esposito [5], definisi singkat dan sederhana permainan video adalah sebuah permainan yang dapat dimainkan karena adanya perangkat audiovisual dan yang bisa didasarkan pada sebuah cerita. Sedangkan menurut Eichenbaum et al [6], permainan video menggunakan sejumlah metode untuk memastikan bahwa pemain tetap tertantang tetapi memiliki quest yang dapat diselesaikan. Sebagian besar permainan video memiliki serangkaian pelatihan awal yang dapat dilewati pemain untuk menunjukkan kompetensi permainan tertentu [7][8].

Permainan video dengan genre action adalah sebuah permainan video yang menekankan tantangan fisik yang memerlukan koordinasi antara tangan, mata, dan koordinasi motorik untuk memenangkan 
permainan tersebut. Penyelesain puzzle, konflik taktik, dan tantangan eksplorasi juga merupakan bagian dari action [9].

Permainan video dengan genre shooter adalah sebuah permainan video yang mengambil tindakan dari jarak jauh dengan bantuan beberapa jenis perangkat mekanis (mouse, gamepad, joystick, dll). Permainan video shooter dibangun berdasarkan kemampuan pemain untuk mengontrol perangkat sehingga mencapai efek yang diinginkan. Permainan video shooter dapat diimplementasikan dalam 2 dimensi ataupun 3 dimensi. Permainan video genre shooter memiliki fundamental berikut ini [10]: Elemen menembak, yaitu lingkungan interaksi pemain dengan objek permainan, lingkungan target, lingkungan avatar pemain dan target dan Alat untuk menembak, yaitu akurasi tembakan, jangkauan tembakan, ukuran peluru, efek kerusakan, rasio tembakan, recoil, dan mode tembakan.

\section{B. Game Development Life Cycle}

Salah satu model proses yang digunakan untuk mengembangkan permainan video adalah Game Development Life Cycle (GDLC) [11][12] [13]. GDLC terdiri dari enam tahapan seperti ditampilkan pada Gambar 1. Tahapan GDLC adalah sebagai berikut [13]: 9!) Tahap inisiasi, penentuan konsep awal ide permainan video mulai dari cara bermain, tema, genre, dan pola permainan video; (2) Tahap pre-produksi, penentuan desain karakter, latar permainan, objek dalam permainan dan piranti lunak yang akan digunakan untuk mengembangkan permainan video; (3) Tahap produksi, perancangan alur aplikasi dan pengkodean dilakukan pada tahap ini; (4) Tahap uji coba, permainan video diuji cobakan secara internal untuk menganalisis keseimbangan dan fungsi permainan. Permainan video diuji coba untuk menemukan bug (jika ada). Tahapan ini merupakan siklus sehingga dapat diulangi dari tahap preproduksi; (5) Tahap beta, permainan video diuji coba secara eksternal, yaitu oleh pengguna secara umum, tujuannya untuk mendapatkan umpan balik pengguna dan review; dan (6) Tahap rilis, permainan video sudah selesai sepenuhnya dan siap dirilis kepada pengguna umum, seperti pada Gambar 1.

\section{Game Maker Studio 1.4}

Game Maker Studio 1.4 adalah sebuah aplikasi game engine yang dapat digunakan untuk membangun game 2 dimensi. Game Maker Studio 1.4 dapat meluncurkan permainan video ke dalam platform Windows, macOS, Linux Ubuntu, HTML5, iOS, Android, Tizen [14]. Game Maker Studio 1.4

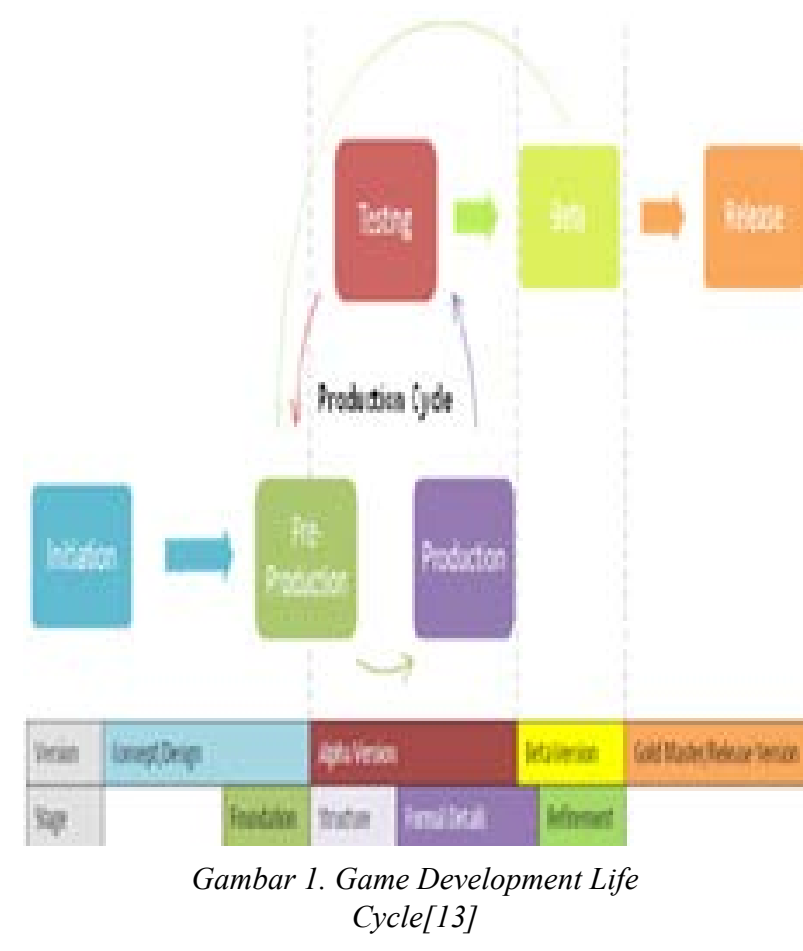

memiliki fitur drag and drop (DND) dan bahasa pemrograman khusus yaitu game maker language (GML) [15]. kedua fitur ini dapat digunakan secara bersamaan. Tampilan awal Game Maker Studio 1.4 ditampilkan pada Gambar 2.

Untuk mulai membuat permainan pada Game Maker Studio 1.4 terlebih dahulu harus membuat objek. Objek ini yang digunakan untuk berinteraksi dengan objek lain sehingga akan menghasilkan mekanik permainan. Terdapat juga sprite, yaitu gambar yang digunakan untuk merepresentasikan objek. Tidak semua objek memerlukan sprite. Objek yang telah dibuat harus dimasukkan ke dalam room agar dapat dimainkan [16][17].

\section{Elemen-elemen Permainan Video}

Elemen formal dalam game adalah sejumlah elemen yang dapat membantu untuk membuat struktur game. Daftar elemen formal yang digunakan

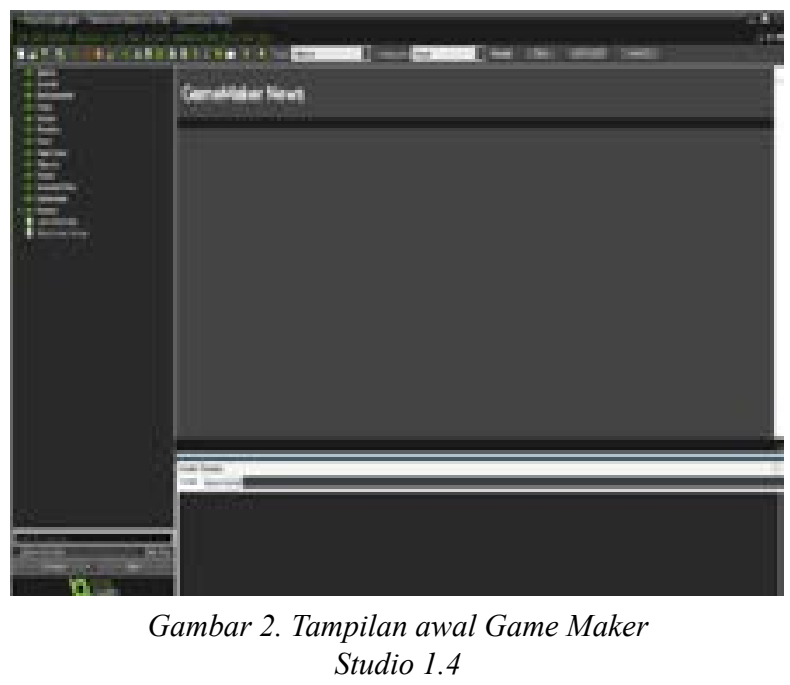


untuk membuat struktur game adalah [18]: Pemain. Pemain adalah pengguna yang memainkan game, bisa pemain tunggal maupun sekelompok orang; Tujuan. Tujuan adalah hal yang dapat dicapai oleh pemain saat memainkan game; Prosedur. Prosedur adalah himpunan instruksi yang diikuti pemain saat memainkan game; Peraturan. Peraturan adalah konsep yang dibuat untuk mengatur hal yang dapat dilakukan dan tidak dapat dilakukan oleh pemain; Sumber daya. Sumber daya adalah nilai yang dimiliki oleh pemain, seperti score, nyawa, waktu, dan lain-lain; Konflik. Konflik adalah hal yang berpotensi mencegah pemain untuk menyelesaikan sebuah tujuan berdasarkan peraturan dan prosedur, contohnya adalah musuh atau hambatan; Batasan. Batasan adalah hal mustahil yang dapat dilakukan oleh pemain di dalam game, seperti pemain tidak dapat keluar dari area permainan; dan Hasil. Hasil adalah suatu hal yang bisa didapatkan oleh pemain setelah mencapai tujuan game.

\section{HASIL DAN PEMBAHASAN}

\section{A. Tahap Inisiasi}

Pada tahap inisiasi dilakukan pengonsepan permainan, deskripsi elemen formal dan elemen dramatis, serta kebutuhan sistem. Konsep permainan ini adalah Permainan video ini dibatasi oleh waktu, yaitu 120 detik. Permainan video ini bergenre actionshooter dengan dua menu utama gameplay, yaitu dengan menembak dan menangkap musuh. Dalam setiap fitur terdapat beberapa item power up seperti penambahan health point, penambahan waktu, dan penambahan bensin. Musuh dalam permainan ini terdiri dari tiga jenis dengan masing-masing jenis memiliki skor dan kekuatan yang berbeda. Pemain dapat berinteraksi dengan menggunakan tombol anak panah dan spacebar. Permainan video ini berjudul Plane vs Aliens. Dalam permainan Plane vs Aliens ini dibuat elemen formal sebagai struktur dasar pengembangan game. Elemen formal Plane vs Aliens ditampilkan pada Tabel 1.

\section{B. Tahap Pra Produksi}

Berdasarkan pengonsepan pada tahap inisiasi, maka pada tahap pra-produksi dihasilkan rancangan struktur navigasi, daftar aset yang digunakan, dan mockup. Pada permainan Plane vs Aliens, struktur navigasi ditampilkan pada Gambar 3. permainan memiliki 6 menu, yaitu mode 1, help mode 1, mode 2, help mode 2, leaderboard, keluar. Jika pemain memilih mode 1, maka akan berpindah ke area permainan 1, yaitu dengan gameplay pemain harus menangkap
Tabel 1 Elemen formal

\begin{tabular}{|c|c|}
\hline $\begin{array}{l}\text { Elemen } \\
\text { Formal }\end{array}$ & Deskripsi \\
\hline Pemain & $\begin{array}{l}\text { Permainan Plane vs Aliens merupakan permainan } \\
\text { single player. Pemain menggerakkan sebuah } \\
\text { pesawat untuk menangkap atau menembak } \\
\text { musuh (alien) }\end{array}$ \\
\hline Tujuan & $\begin{array}{l}\text { Tujuan permainan ini adalah memperoleh nilai } \\
\text { setinggi-tingginya sehingga tercatat pada papan } \\
\text { leaderboard }\end{array}$ \\
\hline Prosedur & $\begin{array}{l}\text { Plane vs Aliens memiliki dua prosedur gameplay. } \\
\text { Pada gameplay 1, pemain menangkap alien untuk } \\
\text { mendapat skor. Untuk setiap alien yang } \\
\text { tertangkap, bensin pesawat yang dimainkan oleh } \\
\text { pemain akan berkurang. Untuk itu, pemain juga } \\
\text { harus menangkap barel bensin. Pada gameplay 2, } \\
\text { pemain menembakkan peluru untuk mengalahkan } \\
\text { alien. Setiap peluru yang ditembakkan akan } \\
\text { mengonsumsi bensin. Untuk dapat terus } \\
\text { menembak, pemain perlu menangkap/menembak } \\
\text { barel bensin. Pada kedua gameplay, alien dapat } \\
\text { menembakkan peluru yang bergerak horizontal. } \\
\text { Pemain dapat menghindari peluru dari alien ini } \\
\text { agar tidak mengurangi bensin. Setiap gameplay } \\
\text { juga dibatasi oleh waktu, yaitu } 120 \text { detik. Pemain } \\
\text { dapat memperoleh waktu tambahan dengan } \\
\text { menangkap/menembak jam. }\end{array}$ \\
\hline Peraturan & $\begin{array}{l}\text { Permainan terbatas oleh waktu selama } 120 \text { detik, } \\
\text { yang dapat diperpanjang dengan menangkap/ } \\
\text { menembak powerup jam waktu. Pada gameplay } \\
\text { 1, bensin pesawat akan berkurang jika mengenai } \\
\text { alien atau peluru alien. Pada gameplay } 2 \text {, bensin } \\
\text { pesawat akan berkurang setiap kali menembak } \\
\text { dan jika mengenai peluru atau peluru alien. Pada } \\
\text { gameplay } 2 \text {, setiap alien memiliki health point. } \\
\text { Health point alien } 1: 5 \text {, alien archer: } 10 \text {, dan alien } \\
\text { warrior: } 15 \text {. Pada gameplay } 2 \text {, setiap perlu yang } \\
\text { ditembakkan dari plane memiliki kekuatan untuk } \\
\text { mengurangi } 5 \text { health point Pemain mendapatkan } \\
\text { skor jika mengenai/ menembak alien. Permainan } \\
\text { akan berakhir apabila bensin pemain habis. Skor } \\
\text { tertinggi akan tercatat di leaderboard. Jumlah } \\
\text { bensin maksimal adalah } 100 \text { liter. Pada gameplay } \\
1 \text {, bensin awal Plane adalah } 10 \text { liter. Pada } \\
\text { gameplay } 2 \text {, bensin awal Plane adalah } 100 \text { liter. }\end{array}$ \\
\hline $\begin{array}{l}\text { Sumber } \\
\text { Daya }\end{array}$ & Skor, bensin, dan waktu \\
\hline Konflik & $\begin{array}{l}\text { Pemain harus mengalahkan alien dengan cara } \\
\text { menangkap atau menembaknya. Serta harus } \\
\text { memperhatikan sisa bensinnya agar permainan } \\
\text { terus berlanjut. }\end{array}$ \\
\hline Batasan & Area permainan dibatasi seluas 1024 x 640 pixel. \\
\hline Hasil & Skor yang ditampilkan di kanan atas layar. \\
\hline
\end{tabular}

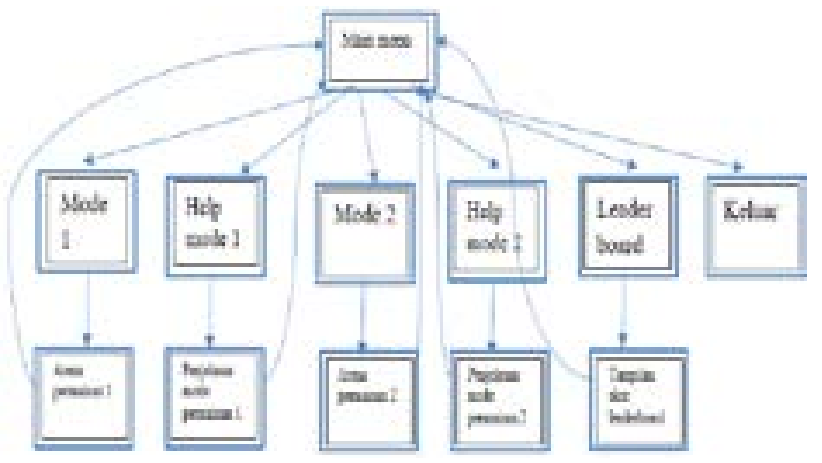

Gambar 3. Struktur navigasi 
alien untuk mendapatkan skor dan menjaga agar bensin tetap tersedia selama waktu permainan masih ada. Jika pemain memilih help mode 2, maka akan berpindah ke scene penjelasan permainan mode 1 .

Pada menu mode 2, pemain akan berpindah ke area permainan 2, yaitu dengan gameplay pemain harus menembak alien untuk mendapatkan skor dan menjaga agar bensin tetap tersedia selama waktu permainan masih ada. Jika pemain memilih help mode 2, maka akan berpindah ke scene penjelasan permainan mode 2. Pada menu leaderboard maka akan berpindah ke scene tampilan skor tertinggi yang pernah diraih oleh pemain. Jika memilih menu keluar, maka aplikasi permainan akan tertutup. Dari setiap scene, pemain dapat kembali ke main menu utama.

Dari konsep struktur navigasi ini, maka selanjutnya menggunakan aset, baik itu gambar ataupun suara untuk proses pengembangan permainan Plane vs Aliens. Daftar aset yang digunakan pada permainan Plane vs Aliens ditampilkan pada Tabel 2.

\section{Tahap Produksi}

Tampilan purwarupa permainan video dari hasil produksi ditampilkan pada Gambar 4 sampai dengan Gambar 8.

Gambar 4 menampilkan room_help yaitu penjelasan cara bermain pada mode 1 . Gambar 5 menampilkan room help2 yaitu penjelasan cara bermain pada mode 2. Gambar 6 menampilkan permainan pada mode 1 , pemain memperoleh skor dengan menabrakkan plane ke alien, namun bensin berkurang. Terdapat barel bensin untuk ditangkap agar bensin bertambah. Gambar 7 menampilkan jika permainan berakhir apabila bensin kurang dari sama dengan 0. Gambar 8 menampilkan form masukan nama pemain apabila masuk ke dalam leaderboard. Gambar 10 menampilkan mode permainan 2. Plane dapat menembakkan peluru untuk mengalahkan alien dan mendapatkan bensin. Gambar 11 menampilkan room_leader_show yang mencatat semua pemain yang masuk ke dalam leaderboard.

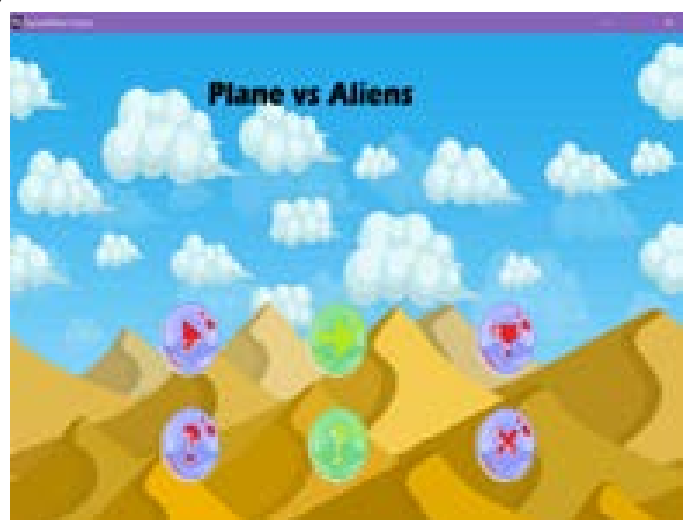

Gambar 4. Tampilan awal

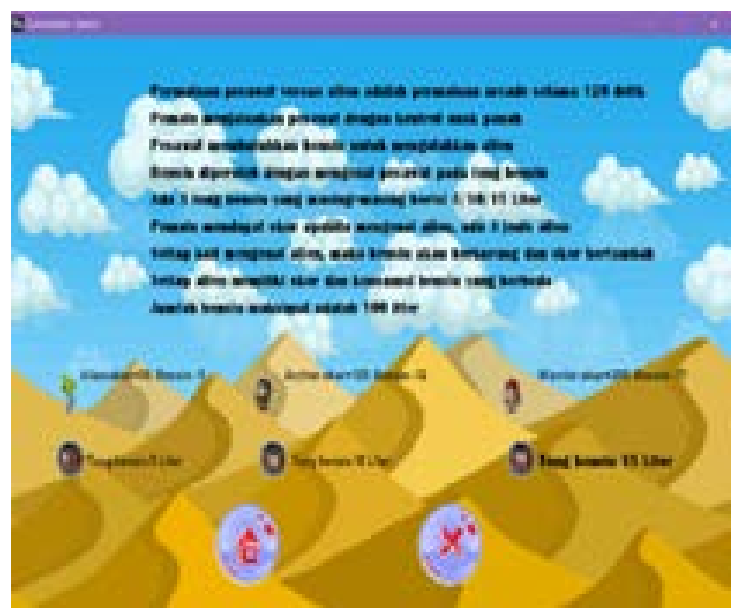

Gambar 5. Tampilan bantuan mode 1

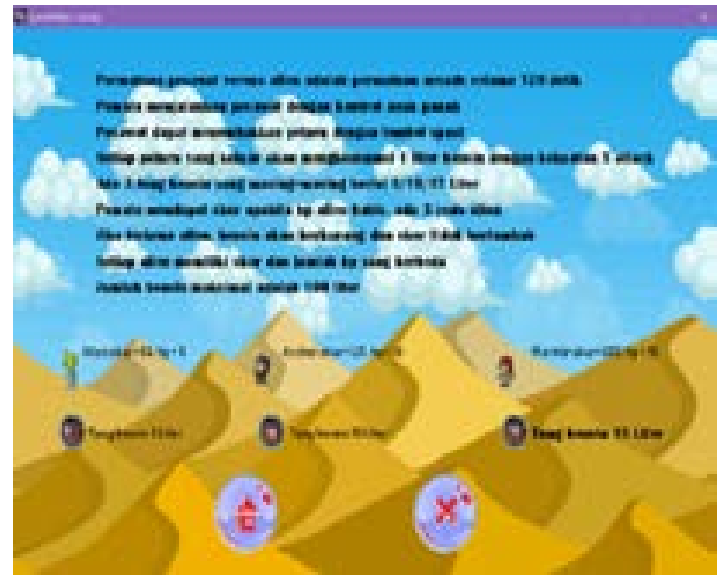

Gambar 6. Tampilan bantuan mode 2

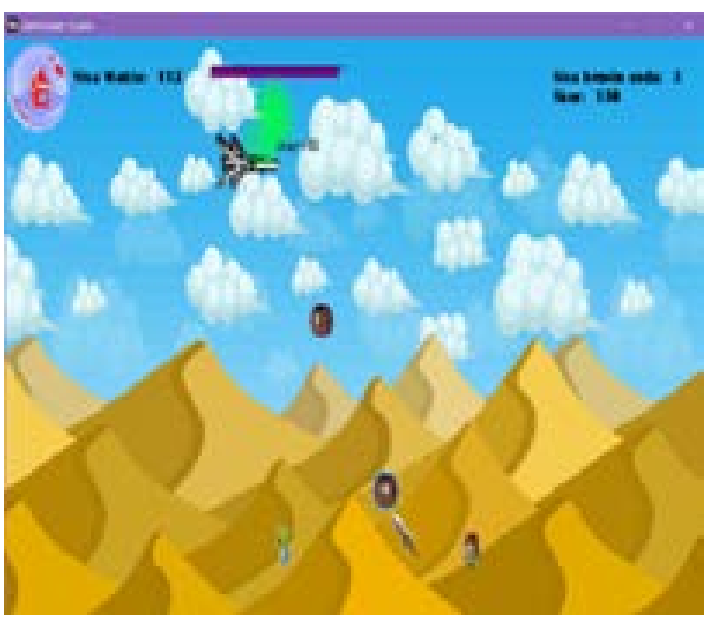

Gambar 7. Tampilan permainan mode 1

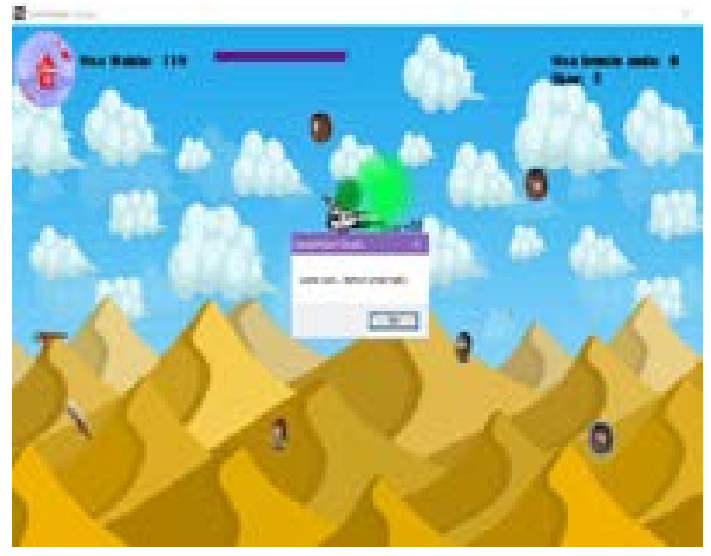

Gambar 8. Tampilan permainan berakhir 


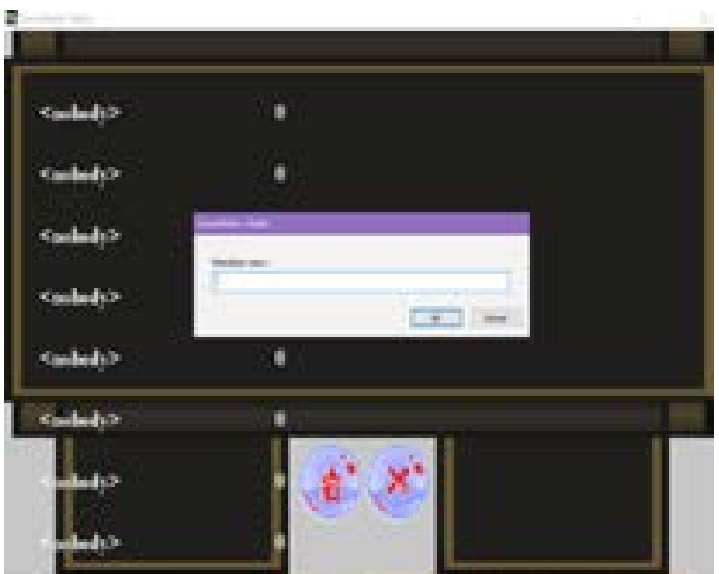

Gambar 9. Tampilan masukan nama pemain

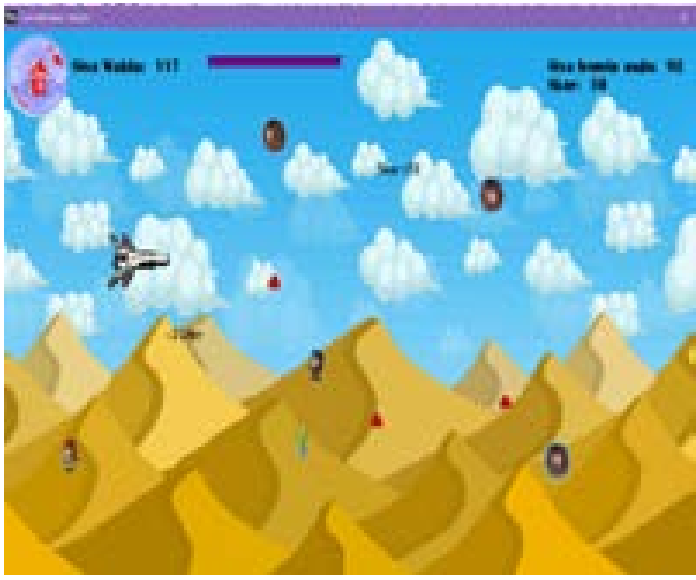

Gambar 10. Tampilan permainan mode 2

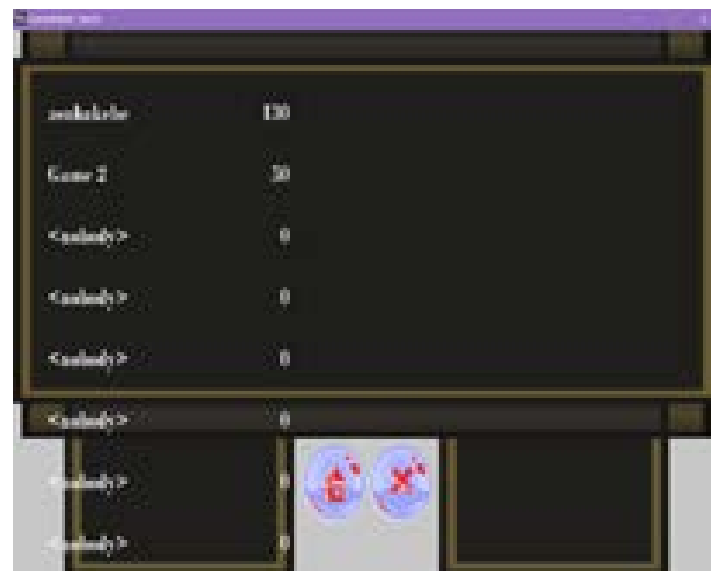

Gambar 11. Tampilan leaderboard

\section{Tahap Testing}

Dari hasil produksi, selanjutnya dilakukan pengujian menggunakan metode pengujian black box. Pengujian ini dilakukan untuk memastikan fungsionalitas pada game yang telah dibuat dapat berjalan sesuai fungsinya

\section{E. Rilis}

Permainan video ini telah dirilis dan dapat diunduh secara bebas melalui laman: https:// tomabekz.itch.io/plane-vs-aliens

\section{SIMPULAN}

Dari proses penelitian ini dapat disimpulkan beberapa hal sebagai berikut: File installer game Plane vs Aliens berhasil dibuat menggunakan Game Maker Studio 1.4; Berdasarkan hasil uji coba black box, seluruh fungsi dalam permainan Plane vs Aliens ini dapat berjalan sebagaimana mestinya; Nilai dan nama pada leaderboard akan selalu reset apabila aplikasi ditutup; dan Permainan Plane vs Aliens ini masih berupa versi Beta dan sudah dirilis.

\section{DAFTAR RUJUKAN}

[1] Statista, "U.S. most popular video game genres 2017," Statista. 2018, [Online]. Available: https://www. statista.com/statistics/189592/breakdown-of-us-videogame-sales-2009-by-genre/.

[2] GamingScan, "2020 Gaming Industry Statistics, Trends \& Data.” 2020, [Online]. Available: https:// www.gamingscan.com/gaming-statistics/.

[3] J. Bisoglio, T. I. Michaels, J. E. Mervis, and B. K. Ashinoff, "Cognitive enhancement through action video game training: Great expectations require greater evidence," Front. Psychol., vol. 5, no. FEB, pp. 1-6, 2014, doi: 10.3389/fpsyg.2014.00136.

[4] I. Granic, A. Lobel, and R. C. M. E. Engels, "The benefits of playing video games," Am. Psychol., vol. 69, no. 1, pp. 66-78, 2014, doi: 10.1037/a0034857.

[5] N. Esposito, "A short and simple definition of what a videogame is," Proc. DiGRA 2005 Conf. Chang. Views - Worlds Play, 2005.

[6] A. Eichenbaum, D. Bavelier, and C. S. Green, "Video Games: Play That Can Do Serious Good.,” Am. J. Play, vol. 7, no. 1, pp. 50-72, 2014.

[7] G. S. Elias, R. Garfield, and K. R. Gutschera, Characteristic of Games. Massachusetts: Massachusetts: The MIT Press, 2012.

[8] T. Fullerton, Game Design Workshop: A Playcentric Approach to Creating Innovative Games, 2nd ed. Elsevier Inc., 2008.

[9] E. Adams, Fundamentals of Game Design. San Francisco: Pearson Education Inc., 2014.

[10] E. Adams, Fundamentals of Shooter Game Design. San Francisco: New Rider, 2015.

[11] R. Adiwikarta and H. B. Dirgantara, "Pengembangan Permainan Video Endless Running Berbasis Android Menggunakan Framework Game Development Life Cycle,” Kalbiscientia J. Sains dan Teknol., vol. 4, pp. 142-148, 2017. 
[12] H. B. Dirgantara, Y. D. Prabowo, and M. M. Jermia, "Development of android-based quiz video game: Mathventure,” Proc. - Int. Jt. Conf. Information, Media, Eng. IJCIME 2019, pp. 450-454, 2019, doi: 10.1109/ IJCIME49369.2019.00097.

[13] R. Ramadan and Y. Widyani, "Game development life cycle guidelines,” 2013 Int. Conf. Adv. Comput. Sci. Inf. Syst. ICACSIS 2013, no. June, pp. 95-100, 2013, doi: 10.1109/ICACSIS.2013.6761558.

[14] R. Ciesla, Mostly Codeless Game Development. 2017.

[15] Yoyogames, “GameMaker Studio 1.4.” 2018.
[16] J. Habgood, M. Overmars, J. Habgood, and M. Overmars, The Game Maker's Apprentice. Apress, 2006.

[17] J. Habgood, N. Nielsen, K. Crossley, and M. Rijks, Game Development : The Game Maker's Companion. Apress, 2010.

[18] L. Nacke, "The formal systems of games and game design atoms." acagamic.com, 2015. 